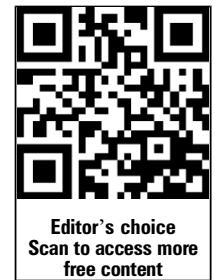

free content
- Additional material is published online only. To view please visit the journal online (http://dx.doi.org/10.1136/ ejhpharm-2012-000274).

${ }^{1}$ Unit for Patient Safety Capital Region of Denmark and Danish Society for Patient Safety,

Copenhagen, Denmark

${ }^{2}$ The Danish Research Unit for Hospital Pharmacy, Amgros, Copenhagen, Denmark

Correspondence to Dr Annemarie Hellebek, Unit for Patient Safety Capital Region of Denmark and Danish Society for Patient Safety, P610, Hvidovre Hospital, Kettegaard Allé 30, Hvidovre, Copenhagen DK-2650, Denmark;

Annemarie.hellebek@regionh. $\mathrm{dk}$

Received 3 January 2013 Revised 23 April 2013 Accepted 25 April 2013 Published Online First 11 June 2013

To cite: Hellebek $A$ Schytte-Hansen S, Fischer $\mathrm{H}$, et al. Eur J Hosp Pharm 2013;20:212-217.

\title{
Patient safety in drug label design: analysis of reported adverse events before and after introducing a new label design
}

\author{
Annemarie Hellebek, ${ }^{1}$ Simon Schytte-Hansen, ${ }^{1}$ Hanne Fischer, ${ }^{2}$ \\ Marianne Hald Clemmensen, ${ }^{2}$ Trine Kart ${ }^{2}$
}

\section{ABSTRACT \\ Objectives To investigate medication errors related to misinterpretation of a new drug label designed with a focus on reducing the risk of medication errors which introduced nine logical features aimed at improving patient safety.}

Method Data on medication errors were collected from the national incidence reporting system, the Danish Patient Safety Database. Medication errors related to misinterpretation of the drug label reported before and after implementation of the new label design were investigated.

Results No overall change in dispensing errors related to misinterpretation of the label before and after introduction of the new design was observed and no substantial changes in specific error types related to features in the new design were evident. However, the present study shows that it is possible to extract valuable information from medication error reports relating the information to specific drugs and specific label features. Conclusions Implementing patient safety in label design for drugs is highly relevant. The overall lack of effect may be caused by factors such as insufficient introduction of the design features among staff as well as inadequate reporting to the incidence reporting system. Using data from incidence reporting systems in the evaluation of initiatives aimed at reducing medication errors requires detailed incidence reports with consistent and high quality data.

\section{INTRODUCTION}

Data from national incidence reporting systems in the UK and Denmark show that dispensing errors constitute $12-18 \%$ of all medication errors ${ }^{1} 2$ and unprevented dispensing errors occur in $0.008-18 \%$ of all dispensing errors in UK and US hospital pharmacies. ${ }^{3}$ Visual misinterpretation of names, labels and packaging play an important part in dispensing errors, resulting in a mix-up between drugs and wrong doses. ${ }^{4-6}$ Such errors are potentially harmful to patients, ${ }^{78}$ and the increasing focus on patient safety and harmful medication errors requires further research into methods of reducing the likelihood of visual misinterpretation.

There are few data in the literature on methods to prevent dispensing errors caused by labelling. The National Patient Safety Agency (NPSA) in the UK has published two reports with guidelines on better label and package design. ${ }^{10}$ The reports are based on literature reviews and involvement of clinicians and designers, but experience with their use has not been scientifically published. Filik et al demonstrated a positive effect on alertness using uppercase ('tall man') lettering of names whereas coloured lettering had no effect. ${ }^{11}$ The use of colours in drug labelling is controversial. Colours used as colour coding may be associated with several problems and may even reduce patient safety whereas the use of colours in colour differentiation (eg, differentiation of strengths) may improve patient safety. ${ }^{12} 13$

In Denmark a substantial proportion of drugs for use in hospitals are produced by Amgros (SAD products), a company owned by the Danish regions. Over the years, reports to the Danish Health and Medicines Authority claims system show that SAD products have occasionally been involved in medication errors. Together with an evolving focus on patient safety, this has led healthcare professionals to call for a change in the labelling of Amgros products. Consequently, the Danish Society for Patient Safety, Amgros and the private foundation TrygFonden organised a design competition with the purpose of introducing a new label design focusing on improving patient safety. The participating design companies were introduced to the NPSA design manuals ${ }^{9} 10$ and to other relevant literature including documents on labelling from the Danish Medicines Agency. ${ }^{14}$ The documents from the Danish Medicines Agency are generally in accordance with documents from the European Medicines Agency on labelling ${ }^{15}$ and include rules on font size, elements that must be part of the label and even how some features must be placed on the label (eg, the strength must be placed right after the invented (trade) name). The designers were informed that the new design should comply with all national regulations. Finally, the designers were invited to talk to clinical staff at Hvidovre University Hospital in Denmark.

The design proposals were evaluated first by a group of clinicians and a group of pharmacists. They presented their conclusions to a jury consisting mainly of designers and patient safety experts. The designers in the jury were introduced to the same material as the participating designers including the NPSA design manual. ${ }^{9}$ The winning design was designed by e-Types and it included nine features aimed at improving patient safety (figure 1 and online supplementary figure S1). The nine features were: larger size of label; use of improved typography and addition of intermittent capitals; use of a 

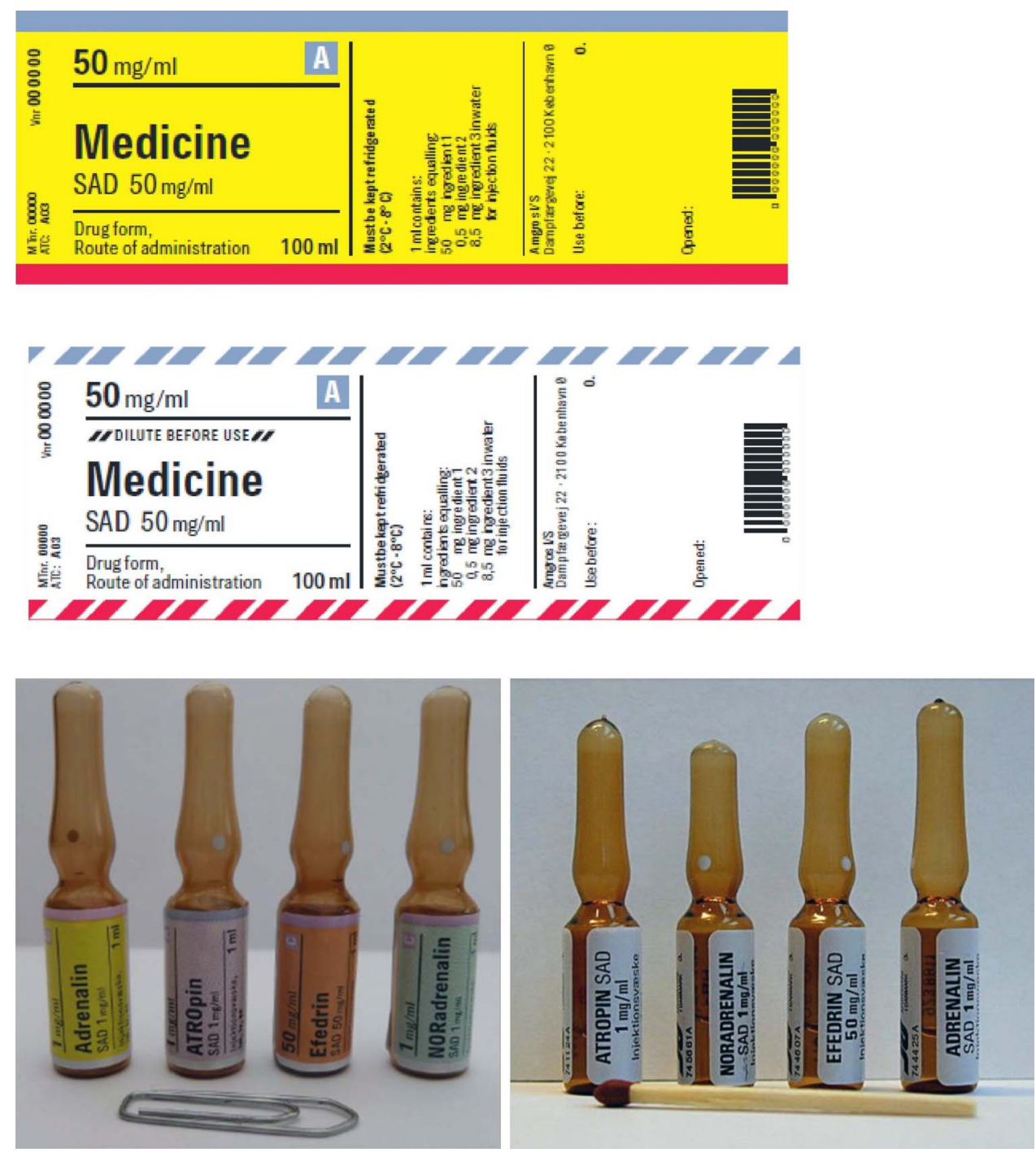

Figure 1 Two examples of the new label: yellow indicates danger, the striped line indicates 'must be diluted' and the capital ' $A$ ' indicates that the drug belongs to the ATC code A combined with the colour code on the top. In the photographs below the new ampoules are on the left and the old ones are on the right.

strength colour code; addition of strength at the upper left corner (except ampullas); yellow fluorescent colour for selected dangerous drugs; code for drugs which must be diluted; room for important information (eg, special route of administration); improved labelling on boxes readable from both top and bottom; and room for additional differentiation (eg, use of shaded colour). The features are shown in figure 1 and in greater detail by e-Types at http://www.e-types.dk/39267.9000/ (accessed 25 March 2013). Online supplementary figure S1 shows a detailed description of the nine features. The design later reached the finals of the global design competition Index Awards. ${ }^{16}$

In Denmark, reporting of medication errors to a national incidence reporting system has been mandatory since $2004 .{ }^{17}$ Data in the reporting system are confidential and used for learning purposes only. The new design of SAD product labels was introduced in 2008, and the purpose of the present study was to compare the patterns of reported errors in 2007 and 2010 for errors related to misinterpretation of the label and to SAD products. To our knowledge, this is the first study in which data from a national incidence reporting system have been used to evaluate label design features specifically developed to improve patient safety.

\section{METHODS}

\section{Data extraction}

The Danish Patient Safety Database (DPSD) is a national database for reporting all types of adverse events in Danish hospitals. The reporting is mandatory by law and staff are protected from prosecution. The reporting of medication errors is mainly in free text which can be searched. The total number of reported medication errors in Denmark was 6781 in 2007 and 10188 in 2010.

In the present study the DPSD was searched for reported medication errors related to SAD products in 2007 and 2010. Medication errors were searched by generic name of all SAD products including often seen misspellings and common ways of spelling such as glucose/glukose or nitroglycerin/glycerylnitrat. A full list of all generic names/search terms can be found in online supplementary figure S2.

\section{Duplicates}

The initial dataset included duplicates since some of the reports included two or more of the search terms. Duplicates were excluded from the reports classified as dispensing errors before further analysis. 


\section{Identification and classification of medication errors related to misinterpretation of label}

Medication errors were classified and validated according to the medication process (prescribing, dispensing, administration, documentation and other). Subsequently, the dispensing errors were classified according to the nature of the error: 'misinterpretation of the label', 'calculation errors', 'no or delayed dispensing', 'application of wrong label at a syringe/bag' and 'others'.

\section{Identification of dispensing errors related to SAD products}

The researchers had access to detailed purchase data from all Danish hospitals. By analysis of purchase data in defined daily doses, it was possible to identify the exact purchase of a specific drug for a specific period at a specific department or hospital. By combining the data on the department and hospital registered in the medication error report with the purchase data from the specific department and hospital, it was possible to identify exactly those medication error reports that involved a SAD product (100\% SAD products). Only medication error reports categorised as 'misinterpretation of the label' were subsequently analysed. In addition, the overall market share for SAD products was calculated.

\section{Classification for harm}

Dispensing medication errors categorised as 'misinterpretation of label' and caused by SAD products were classified for harm using the WHO classification scale ${ }^{18}$ with the addition of a score (9) for unknown harm and a score for near misses (0).

\section{Classification related to label design}

Errors related to misinterpretation of the label involving a SAD product were categorised according to three warning features and a group containing the rest of the nine features: 'dangerous drugs coding' (adrenaline, suxamethone and potassium chloride), 'strength colour code' (B-combin strong, bupivacaine, digoxine (tabl), phenemal, glucose, heparin, lidocaine, lidocaineadrenaline, lidocaine-noradrenaline, morphine, sodium bicarbonate, sodium chloride, pethidine, suxamethone, theophyllamine), 'dilution code' (acetylcysteine, glyceryl trinitrate, potassium chloride, magnesium sulfate, sodium bicarbonate, sodium chloride, zinc sulfate) and 'other features' (the remaining six features). If a medication error report implicated a SAD product with several features in the design, it would be included in all relevant categories. If an error report implicated two SAD products, both products would be accounted for and categorised.

All categorising was done by two independent researchers. Differences in scoring were solved by consensus.

\section{Statistical analysis}

All data were collated and organised by a spread sheet programme (Excel 2007) and descriptive statistics were used.

\section{RESULTS}

Analysis of purchase data revealed that the market share of SAD products remained stable from 2007 to 2010 (see online supplementary figure S3).

In 2007 a total of 1642 medication error reports were identified where at least one of the products involved could be a SAD product. For 2010 the number was 2122 reports. The distribution of medication error reports according to steps in the medication process is shown in figure 2. A total of 951 unique medication errors related to dispensing were identified and subsequently categorised according to the nature of the error (table 1).

\section{Dispensing errors (possible SAD product): nature of the errors}

Reported dispensing errors that included a product which may be a SAD product increased from 435 in 2007 to 516 in 2010. The number of dispensing errors relative to all medication errors where at least one product could be a SAD product decreased from $27 \%$ in 2007 to $24 \%$ in 2010 . The percentage of errors related to misinterpretation of the label was reduced by $11 \%$ in the same period from $60 \%$ in 2007 to $49 \%$ in 2010 (table 1).

\section{Dispensing errors (100\% SAD products): harm score}

Using the purchase data it was possible to identify a total of 165 medication errors categorised as 'misinterpretation of label' which included at least one SAD product 85 in 2007 and 80 in 2010). The harm score for these errors did not differ between the two periods (table 2).

\section{Dispensing errors (100\% SAD products): relation to label design}

We identified 126 problems related to label features in 2007 and 117 in 2010 (table 3). Comparison of the errors related to specific label features revealed a significant difference between groups over time $(\mathrm{p}<0.05)$. In particular, a numerically small and non-significant decrease in errors related to the strength colour code was observed $(p=0.07)$ whereas errors related to other features significantly increased after implementation of the new label design $(p=0.03$; table 3$)$.

Further analysis of error patterns for the individual drugs showed that there was no consistent pattern combining label features and individual drugs. However, for some of the individual drugs there were considerable numerical differences between reported errors for the 2 years. In particular, the number of errors with epinephrine (adrenaline) increased while there was a
Figure 2 Classification and distribution of medication errors identified in the Danish Patient Safety Database.
3764 reported MEDICATION

ERRORs were identified
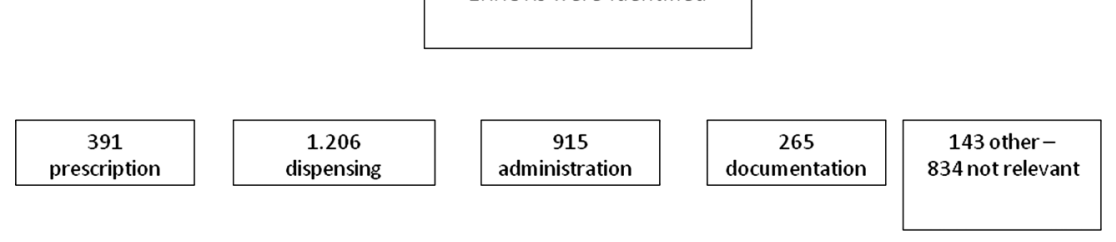
Table 1 Categorisation and distribution of reported dispensing errors

\begin{tabular}{|c|c|c|c|c|c|c|}
\hline \multirow[b]{2}{*}{ Year } & \multicolumn{6}{|l|}{ Category } \\
\hline & Misinterpretation of label & Calculation errors & No or delayed dispensing & Application of wrong label at syringe/bag & Others & Total \\
\hline 2007 & $262(60 \%)$ & $48(11 \%)$ & $38(9 \%)$ & $15(3 \%)$ & $72(17 \%)$ & $435(27 \%)$ \\
\hline 2010 & $254(49 \%)$ & $62(12 \%)$ & $83(16 \%)$ & $18(3 \%)$ & $99(19 \%)$ & $516(24 \%)$ \\
\hline
\end{tabular}

Percentage is calculated as a percentage of the total dispensing errors for the respective years. The percentage provided for the total number of dispensing errors is calculated relative to the total number of medication reports identified which may include a SAD product.

decrease in the number of errors with potassium chloride $(\mathrm{KCl})$ infusion, $\mathrm{KCl}$ oral solution and lidocaine (table 4).

\section{DISCUSSION}

In the present study the overall frequency of reported dispensing errors related to misinterpretation of the label including at least one SAD product did not change substantially with the implementation of a new label design. The new label design has incorporated several features aimed at reducing the risk for medication errors. Subsequent analysis of errors related to specific features of the design (dangerous drugs code, dilution code and strength colour code) was performed and no differences in the overall patterns were found. However, in a few cases considerable differences were observed when error patterns for the individual drugs were analysed.

The introduction of the new label design did not result in an overall decrease in the total number of reported errors that could be related to misinterpretation of the label and to a SAD product. The lack of a clear overall effect may be due to several factors. The new label design builds on logics and does, to some extent, require that users have a basic knowledge of the system. The lack of effect may therefore be caused by inadequate implementation of the codes and rules in the label system among the staff. In support of this, a simulation study on the same label design indicated that the implementation of the label features among the clinical staff had not been successful. One might speculate that, once staff have learnt the features of the design, it will be useful for them and will support the desired safety effect of the label features (unpublished observations).

Another factor influencing the results is the increasing focus on patient safety and incidence reporting in the study period. Between the 2 years there was an overall increase (almost double) in reports to the DPSD. However, a similar increase was not evident for dispensing errors possibly involving a SAD product. On the contrary, an overall reduction of $11 \%$ in errors

Table 2 WHO harm scores of reported dispensing medication errors in which at least one of the products is a SAD product in 2007 and 2010

\begin{tabular}{lcc}
\hline WHO harm score & $\mathbf{2 0 0 7}$ & $\mathbf{2 0 1 0}$ \\
\hline Near miss & 21 & 24 \\
None & 36 & 24 \\
Mild & 17 & 25 \\
Moderate & 3 & 4 \\
Severe & 3 & 1 \\
Death & 1 & 1 \\
Unknown & 4 & 1 \\
Total & 85 & 80 \\
\hline
\end{tabular}

related to misinterpretation of labels was observed. At the same time, purchase data showed that the market share of SAD products remained stable from 2007 to 2010. Thus, the consistent or even reduced numbers of reported errors related to labels could be taken as a positive sign when taking into account the overall increase in the number of reported errors over time.

The use of colours in several of the features of the design may also have had a negative impact on the outcome. Some literature recommends against using colour coding systems and suggests that colour coding systems may even be error-prone. Instead, a more chaotic differentiating system is recommended. ${ }^{12}$ Colour coding systems imply a systematic use of colours to classify products whereas colour differentiation uses colours to emphasise certain features and help to distinguish one item from another. Indeed, other studies indicate that colour differentiation (as used in the present design to separate strengths) may improve the accuracy of drug identification. ${ }^{13}$ This is in line with the observed numerical decrease in errors related to the strength colour code in the present study. In contrast, however, no change in errors related to the dangerous drug code was observed which, in the present design, represents the more chaotic use of colour differentiation.

Despite the lack of a clear overall effect of the new label design, subsequent analysis of the specific drugs revealed considerable numerical changes for some of the drugs. Indeed, an increase in the number of errors was observed for epinephrine. It has not been possible to identify a single conclusive explanation for this increase, but analyses of the medication error reports implicating epinephrine indicate a general challenge when administering drugs in ampoules. Look-alike confusion is a type of medication error often reported, particularly when administering drugs in ampoules. ${ }^{2}{ }^{19}$ It is therefore possible that further initiatives beyond optimisation of the label are needed for this group of drugs.

Interestingly, a decrease in the number of reported errors was observed for $\mathrm{KCl}$ infusion, $\mathrm{KCl}$ oral solution as well as for lidocaine solution for injection. In the case of $\mathrm{KCl}$ infusion and $\mathrm{KCl}$ oral solution, a detailed analysis revealed several cases in 2007 where the infusion was mistaken with the oral solution. In 2010

Table 3 Number of error reports related to specific label features reported in 2007 and 2010

\begin{tabular}{lcc}
\hline Label feature & $\mathbf{2 0 0 7}$ & $\mathbf{2 0 1 0}$ \\
\hline Dangerous drugs code & 16 & 16 \\
Strength colour code & 67 & 44 \\
Dilution code & 12 & 10 \\
Other features & 31 & 47 \\
Sum & 126 & 117 \\
\hline
\end{tabular}


Table 4 Individual number of error reports for SAD-products in 2007 and 2010

\begin{tabular}{|c|c|c|}
\hline SAD-products & 2007 & 2010 \\
\hline \multicolumn{3}{|l|}{ Dangerous drugs code } \\
\hline Adrenalin & 2 & 11 \\
\hline $\mathrm{KCl}$ infusion* & 10 & 1 \\
\hline Suxameton* & 4 & 4 \\
\hline \multicolumn{3}{|l|}{ Strength colour code } \\
\hline Na-Bicarbonat & 1 & 6 \\
\hline Bupivacain & 5 & 2 \\
\hline Bupivacain morfin & 2 & 2 \\
\hline Fenemal & 0 & 2 \\
\hline Glukose & 15 & 12 \\
\hline Heparin & 3 & 0 \\
\hline Lidocain & 15 & 3 \\
\hline Lidocain-adrenalin & 5 & 1 \\
\hline Lidocain-noradrenalin & 1 & 0 \\
\hline Morfin & 9 & 5 \\
\hline $\mathrm{NaCl}$ & 4 & 2 \\
\hline $\mathrm{NaCl}$ hyperton* & 0 & 1 \\
\hline Petidin & 1 & 2 \\
\hline Suxameton* & 4 & 4 \\
\hline Tablets & 2 & 2 \\
\hline \multicolumn{3}{|l|}{ Dilution code } \\
\hline Na-Bicarbonat concentrate & 0 & 1 \\
\hline Glycerylnitrat & 0 & 7 \\
\hline Magnesium sulfat & 2 & 0 \\
\hline $\mathrm{NaCl}$ hyperton* & 0 & 1 \\
\hline $\mathrm{KCl}$ infusion* & 10 & 1 \\
\hline \multicolumn{3}{|l|}{ Other features } \\
\hline Atropin & 0 & 6 \\
\hline Elektrolyt infusion & 8 & 15 \\
\hline Calciumchlorid & 1 & 0 \\
\hline Efedrin & 5 & 7 \\
\hline $\mathrm{KCl}$ oral solution & 7 & 0 \\
\hline Kodein oral solution & 1 & 0 \\
\hline Metaoxedrin & 2 & 3 \\
\hline Noradrenalin & 0 & 9 \\
\hline Tiomebumal-Na & 0 & 1 \\
\hline Tablets & 7 & 3 \\
\hline Suppositories & 0 & 3 \\
\hline Total number including double features & 126 & 117 \\
\hline
\end{tabular}

no such cases were identified, indicating that a change in behaviour when dispensing these drugs had occurred. From the current results it is not possible to conclude that the decrease in errors with $\mathrm{KCl}$ infusion and $\mathrm{KCl}$ oral solution was caused by the new label design, however the introduction of the dangerous drugs code to the $\mathrm{KCl}$ infusion together with a specific marking of 'oral solution' on the $\mathrm{KCl}$ oral solution may indeed have improved patient safety when dispensing these drugs. In addition, other initiatives such as replacement of drugs and campaigns at different hospital departments may have had a positive effect on errors with these drugs.

As with epinephrine, no single factor could be identified to account for the errors involving lidocaine. Lidocaine is a complex product that exists in different concentrations, different formulations and in different combinations with, for example, epinephrine and norepinephrine. Despite this complexity, the number of errors involving lidocaine decreased substantially over time, indicating that patient safety when dispensing this drug has improved. It is possible that the new label design and the features introduced to the lidocaine label have had a positive effect on patient safety; however, no clear conclusion can be drawn from the current results and other factors mentioned above may equally have had an effect on the patient safety for lidocaine.

The present study shows that data obtained from medication error reports can reveal some valuable information about patient safety in relation to a specific drug. However, performing a qualitative analysis of data from medication error reports requires a very high degree of standardisation of the reported data to obtain reports of high quality. This study clearly points out the difficulties in analysing reported errors. In many cases the error reports were described at a superficial level and the medication error reports did not include the pharmaceutical company that had delivered the drug involved. For the final analyses we included only medication error reports in which we were $100 \%$ sure that the market holder of the particular ward was SAD, thereby excluding more than half of the reports. For some of the wards, SAD had $50 \%$ or even $90 \%$ of the market, but it was not possible to extract from the medication error reports which company was involved and it was therefore not possible to include these reports in the final results. An improvement in the quality of the data reported to the DPSD would be desirable for future studies and would allow more clear conclusions to be drawn. To increase further the usability of error reports from staff, an educational effort is needed and error reporting databases should facilitate easy inclusion of details of drugs for dispensing errors. Moreover, it is widely accepted that incidence reporting may only reveal the top of the iceberg and may be sensitive to several other factors such as differences in safety culture among different healthcare professionals. $^{20} 21$ Indeed, this should also be taken into account when analysing this kind of data, and it should be emphasised that the results reported in the current study are highly susceptible to these challenges. Thus, the lack of effect reported in this study may be challenged by the difficulties of applying quantitative analysis to this kind of data. However, looking for trends and changes of pattern in the reported errors may add valuable information about the effect of specific efforts to improve patient safety, as illustrated in the present study where medication error reports could be related to specific drugs and specific drug label features. It may also be a valuable tool in identifying specific patient safety problems that should be addressed. This approach is important for the drugs industry and for the regulatory bodies, so medication errors have been included in the definition of adverse drug event in Europe.

Improving drug label design may indeed improve patient safety in the medication process. However, the design of the drug label design cannot stand alone and must include other initiatives such as barcode scanning, automated alerts and appropriate organisation of medication rooms. ${ }^{6} 22$

In conclusion, dispensing errors related to misinterpretation of labels remains a problem and thus research into proper label design remains a relevant topic. Using reported medication errors as a data source for this research is possible, but improved quality of data and the inclusion of data to identify the exact drug are necessary. 
Key messages

What is already known on this subject

- Numerous reports on medication errors indicate that health care professionals mix up and misunderstand medication labelling.

- Previous studies have focused on reducing mix up in medication names using small-scale laboratory studies.

- In this study we evaluated a whole new safety design concept for medicines from a specific company using reported medication errors.

\section{What this study adds}

- The study demonstrated the difficulties arising when using reported medication errors as efficacy variable.

- The study showed that data obtained from medication errors reports may reveal valuable information about patient safety in relation to specific drugs.

Acknowledgements The authors thank the National Agency for Patients' Rights and Complaints for their assistance in accessing anonymised data in the National Database for Inadvertent Incidents.

Funding This study was supported by a grant from TrygFonden. TrygFonden has had no involvement in the present study.

Competing interests TK, HF and MHC are employed at Amgros, which is the holder of the marketing authorisation of SAD products. Amgros is a non-commercial company and has no economic interest in the present study.

Provenance and peer review Not commissioned; externally peer reviewed.

\section{REFERENCES}

1 National Patient Safety Agency. Safety in doses: improving the use of medicines in the NHS. 2009. http://www.nrls.npsa.nhs.uk/resources/?Entryld45=61625 (accessed 22 Aug 2012).

2 Sundhedsstyrelsen. Temarapport 2005: Medicinering. 2005. http://dpsd.dk/upload/ medicinering 004.pdf (accessed 22 Aug 2012).

3 James KL, Barlow D, McArtney R, et al. Incidence, type and causes of dispensing errors: a review of the literature. Int I Pharm Pract 2009;17:9-30.

4 Cohen M. The role of drug packaging and labelling in medication errors. Washington: American Pharmacist Association, 2007:111-52.
5 Berman A. Reducing medication errors through naming, labeling, and packaging. J Med Syst 2004;28:9-29.

6 Emmerton LM, Rizk MF. Look-alike and sound-alike medicines: risks and 'solutions'. Int J Clin Pharm 2012;34:4-8.

7 Schulmeister L. Look-alike, sound-alike oncology medications. Clin I Oncol Nurs 2006;10:35-41.

8 Hoffman JM, Proulx SM. Medication errors caused by confusion of drug names. Drug Saf 2003;26:445-52.

9 National Patient Safety Agency. Design for patient safety: a guide to the design of dispensed medicines. 2007. http://www.nrls.npsa.nhs.uk/resources/collections/ design-for-patient-safety/?entryid45=59829 (accessed 22 Aug 2012).

10 National Patient Safety Agency. Design for patient safety: a guide to labelling and packaging of injectable medicines. 2008. http://www.nrls.npsa.nhs.uk/resources/ collections/design-for-patient-safety/?entryid45=59831 (accessed 22 Aug 2012).

11 Filik R, Purdy K, Gale A, et al. Labeling of medicines and patient safety: evaluating methods of reducing drug name confusion. Hum Factors 2006;48:39-47.

12 Institute for Safe Medication Practices. A spectrum of problems with using color. Medication Safety Alert. 2003. http://www.ismp.org/newsletters/acutecare/articles/ 20031113.asp (accessed 1 Oct 2012).

13 Hellier E, Tucker M, Kenny N, et al. Merits of using color and shape differentiation to improve the speed and accuracy of drug strength identification on over-the-counter medicines by laypeople. J Patient Saf 2010;6:158-64.

14 Bekendtgørelse om mærkning m.m. af lægemidler. 2011. https://www. retsinformation.dk/Forms/R0710.aspx?id=138137 (accessed 25 Mar 2013).

15 European Commission. Guideline on the readability of the labeling and package leaflet of medicinal products for human use. Revision 1. 2009. http://ec.europa.eu/ health/files/eudralex/vol-2/c/2009_01_12_readability_guideline_final_en.pdf (accessed 25 Mar 2013).

16 Index: Award. 2012. http://www.designtoimprovelife.dk/index.php? option=com_content_custom\&view=category\&id $=10$ :

finalists-2009\&ltemid=293\&layout=default (accessed 12 Sep 2012).

17 National Board of Health. Danish Patient Safety Database. 2007. http:/l patientsikkerhed.dk/fileadmin/user_upload/documents/About/ Danish_Patient_Safety_Database.pdf (accessed 22 Aug 2012).

18 WHO. Conceptual Framework for the International Classification for Patient Safety. 2009. http://www.who.int/patientsafety/taxonomy/icps_full_report.pdf (accessed 22 Aug 2012).

19 Llewellyn RL, Gordon PC, Wheatcroft D, et al. Drug administration errors: a prospective survey from three South African teaching hospitals. Anaesth Intensive Care 2009;37:93-8.

20 Meyer-Massetti M, Cheng CM, Schwappach DLB, et al. Systematic review of medication safety assessment methods. Am J Health-Syst Pharm 2011;68:227-40.

21 Ashcroft DM, Cooke J. Retrospective analysis of medication incidents reported using an on-line reporting system. Pharm World Sci 2006;28:359-65.

22 Mahmood A, Chaudhury H, Valente M. Nurses' perceptions of how physical environment affects medication errors in acute care settings. App/ Nurs Res 2011;24:229-37. 